Filol. Linguíst. Port., São Paulo, v. 17, n. 1, p. 101-129, jan./jun. 2015 http://dx.doi.org/10.11606/issn.2176-9419.v17i1p101-129

\title{
Cortesia verbal e ensino de língua: reflexóes sobre competência comunicativa, jogo interpessoal e normatividade
}

\author{
Politeness and verbal language education: \\ reflections on racing comunicativa, \\ interpersonal game and normativity
}

\author{
Leonor Lopes Fávero* \\ Universidade de São Paulo e Pontifícia Universidade \\ Católica de São Paulo, São Paulo, São Paulo, Brasil \\ Maria Lúcia C. V. O. Andrade ** \\ Universidade de São Paulo, São Paulo, São Paulo, Brasil
}

\begin{abstract}
Resumo: A partir de uma perspectiva pragmática, este artigo busca refletir sobre a necessidade de se trabalhar a cortesia verbal no ensino de língua portuguesa, em suas modalidades oral e escrita, observando como se instaura o jogo interpessoal em contextos sociais diversos. Torna-se evidente a necessidade de discussão dos fatores sociais implicados na expressão da cortesia, bem como da capacidade de expressar e interpretar as funçóes comunicativas e o conhecimento das normas. $\mathrm{O}$ trabalho examina a cortesia em interaçôes orais e escritas (registro formal/semiformal), tendo como objeto de análise textos do século XX, a saber, entrevistas de televisão,
\end{abstract}

* Professora titular aposentada do Departamento de Linguística da Faculdade de Filosofia, Letras e Ciências Humanas da Universidade de São Paulo - USP, São Paulo, São Paulo, Brasil, e, atualmente, professora titular de Língua Portuguesa, na Faculdade de Letras da Pontifícia Universidade Católica de São Paulo - PUC-SP, São Paulo, Brasil; também faz parte da equipe de pesquisadores do Projeto NURC/SP ; é pesquisadora do CNPq; lplfavero@uol.com.br

** Professora da Área de Filologia e Língua Portuguesa, no âmbito da graduação e pós-graduação, na Faculdade de Filosofia, Letras e Ciências Humanas da Universidade de São Paulo - USP, São Paulo, São Paulo, Brasil, e pesquisadora do Projeto NURC/SP; maluvictorio@uol.com.br 
entrevistas posteriormente impressas, bem como cartas pessoais (trocadas entre amigos ou familiares) e publicadas em coletâneas de estudos literários. Também faz parte deste artigo uma breve reflexão sobre o tratamento da oralidade e da escrita no ensino de língua portuguesa, visando a sugerir aos professores de ensino fundamental e médio como trabalhar a cortesia verbal nas atividades cotidianas (conversas, entrevistas, cartas, bilhetes), contribuindo para que o aluno possa desempenhar seu papel social adequadamente por meio de variadas práticas discursivas.

Palavras-chave: Cortesia. Oralidade. Escrita. Contexto. Ensino de língua.

Abstract: From a practical perspective, this chapter seeks to reflect on the need to incorporate verbal politeness in the teaching of the Portuguese language, both oral and written modes, considering how the interpersonal interaction in various social contexts is established. Clearly a discussion on social factors involved in politeness expression is needed, as well the ability to convey and interpret the communicative functions and knowledge of the rules. This paper examines the politeness in oral and written interactions (formal/semiformal register), taking into account texts from the twentieth century as object of analysis, namely, television interviews, interviews printed later on as well as personal letters (exchanged between friends or family members) and published in collections of literary studies. This chapter also brings a brief reflection on how oral communication and writing are dealt in teaching of the Portuguese language. Our aim is to propose to elementary, secondary and high school teachers ways to work with verbal politeness in daily activities (conversations, interviews, letters, notes). Such tasks will hopefully aid students to perform their social role accordingly through various discursive practices.

Keywords: Politiness. Orality. Writing. Context. Language teaching.

Fávero LL, Andrade MLCVO. Cortesia verbal e ensino de língua: reflexôes sobre competência comunicativa, jogo interpessoal e normatividade 


\section{CONSIDERAÇÓES INICIAIS}

Em trabalhos anteriores (Fávero, Andrade, Aquino, 19981, 2000a e 2000b), Fávero (2008), Andrade (2008) vimos que a cortesia ${ }^{2}$ pode ser concebida como um conjunto de normas sociais que cada comunidade estabelece para regular o comportamento adequado de seus membros, ajustando atitudes às normas.

$\mathrm{Na}$ visão de Alvarez-Muro (2005), nem sempre, porém, os indivíduos de diferentes grupos sociais agem de modo semelhante, dependendo de certos costumes, tradiçôes e fatores culturais e, embora a variedade sempre tenha existido, esta época de globalização tem contribuído com o destaque de determinados comportamentos, daí a necessidade de explicação para nossos acertos e desacertos comunicativos cotidianos. Vivemos um tempo de questionamentos sociais e é importante discutir o que há em nosso comportamento verbal que pode nos tornar desiguais, ainda que sejamos seres humanos iguais perante a lei dos homens.

A partir de uma perspectiva pragmática, este artigo busca refletir sobre a necessidade de se trabalhar a cortesia verbal no ensino de língua portuguesa, em suas modalidades oral e escrita, observando como se instaura o jogo interpessoal em contextos sociais diversos. Torna-se evidente a necessidade de discussão dos fatores sociais implicados na expressão da cortesia, bem como da capacidade de expressar e interpretar as funçóes comunicativas e o conhecimento das normas.

O trabalho examina a cortesia em interaçóes orais e escritas (registro for$\mathrm{mal} /$ semiformal), tendo como objeto de análise textos do século XX, a saber, entrevistas de televisão, entrevistas posteriormente impressas, bem como cartas pessoais (trocadas entre amigos ou familiares) e publicadas em coletâneas de estudos literários.

Também faz parte deste artigo uma breve reflexão sobre o tratamento da oralidade e da escrita no ensino de língua portuguesa, visando a sugerir aos professores de ensino fundamental e médio como trabalhar a cortesia verbal nas atividades cotidianas (conversas, entrevistas, cartas, bilhetes), contribuindo para que o aluno possa desempenhar seu papel social adequadamente por meio de variadas práticas discursivas.

1 Trabalho apresentado durante o colóquio "A investigação do português na África, América, Ásia e Europa”, em Berlim, no Ibero-Amerikaniaches Institut, em março de 1998 e depois publicado em 2000a.

2 Cortesia é uma palavra polissêmica. Empregamo-la aqui como sinônimo de polidez.

Fávero LL, Andrade MLCVO. Cortesia verbal e ensino de língua: reflexôes sobre competência comunicativa, jogo interpessoal e normatividade 


\section{OS PRIMEIROS ESTUDOS SOBRE CORTESIA}

O tema da cortesia foi, por muito tempo, ignorado por gramáticos e linguistas, com exceção, segundo Kerbrat-Orecchioni (2005, p. 189), de Dauzat - La défense de la langue française (1912), Bally - Le langage et la vie (1913) et Brunot - La pensée et la langue (1922) que tratam da questão numa perspectiva linguística, "mais par la bande".

Bally, por exemplo, assim se expressa:

A cortesia imprime sua marca em partes profundas da gramática; podemos citar em francês o emprego do plural de cortesia e uma grande variedade de nuances modais, como o uso do futuro e o condicional nas questôes imperativas (1913/1977, p. 104 in Kerbrat-Orecchioni, 2005, p. 190) ${ }^{3}$.

Mas, no final da década de 70 a situação muda, aparecendo nos Estados Unidos inúmeros trabalhos sobre ela de tal modo que se pode dizer, com Kerbrat- Orecchioni (2005, p. 190) que "ela se torna um dos temas de pesquisa mais importantes em pragmática e em sociolinguística”.

Para Goffman $(1967,1973,1981)$, todas as pessoas necessitam preservar seu território e sua face (que se pode perder ou ganhar), entendendo-se território (corporal, espacial, de bens materiais, temporal, etc), tanto no seu sentido próprio como no metafórico.

O termo face pode ser definido como o valor social positivo que uma pessoa reivindica para si de forma eficaz na perspectiva que os outros assumem que ele tomou durante um contato específico. Face é uma imagem de si delineada em termos de atributos aprovados socialmente. (Goffmann, 1967, p. 5) ${ }^{4}$.

3 No original: "La politesse imprime sa marque sur des parties profondes de la grammaire; on peut citer en français le pluriel de politesse, toute une gamme des nuances modales, par exemple l'emploie du futur et du conditionnel dans des interrogations impératives" (1913/1977, p. 104 in Kerbrat-Orecchioni 2005, p. 190).

$4 \quad$ No original: "The term face may be defined as the positive social value a person effectively claims for himself by the line others assume he has taken during a particular contact. Face is an image of self delineated in terms of approved social attributes". (Goffmann, 1967, p. 5).

Fávero LL, Andrade MLCVO. Cortesia verbal e ensino de língua: reflexôes sobre competência comunicativa, jogo interpessoal e normatividade 
A distinção entre face e território nem sempre é fácil ou interessante de ser feita, porém é útil em um grande número de casos quando há, por exemplo, interesses conflitantes, ou, em certas culturas que privilegiam um ou outro. (Kerbrat-Orecchioni, 2005).

Segundo Goffman, ainda, a negociação origina-se sempre em um conflito ou divergência e, a partir de uma discussão, busca-se chegar a um acordo; não há situação de fala que não exija de cada participante uma preocupação sobre como tratar a si mesmo e aos outros. Para Bernal (2005, p. 366), "a imagem tem um caráter público e interpessoal”, isto é, o indivíduo, diante de outro, projeta, consciente ou inconscientemente um retrato da situaçáo em que o conceito de si mesmo é parte essencial, isto é, ele deseja preservar sua auto-imagem.

Lakoff (1973), uma das pioneiras no estudo da cortesia, partindo das máximas de Grice, e procurando mostrar que nem sempre elas precisam ser respeitadas, propóe uma série de regras, com a intenção de restringir ao máximo a possibilidade de conflito:

- não imponha sua vontade;

- $\quad$ indique opçóes;

- $\quad$ seja amistoso 5 .

Leech (1983) afirma, mais tarde, que a relação entre os interlocutores impóe seleçôes que determinam o significado e matizam sua significação e ou se mantém o equilíbrio dessa relação ou é preciso modificá-la e é pela cortesia que se regula a distância social e seu equilíbrio, já que é por seu intermédio que mantemos a distância ou a diminuímos.

$\mathrm{O}$ autor estabelece uma classificação, não estanque, de categorias de açôes: ações que instauram a cortesia (agradecer), açóes que nela não interferem (informar), açóes que entram em conflito com ela (ordenar) e açóes que inviabilizam o bom relacionamento (acusar).

No Dicionário de Análise do Discurso de Charaudeau e Maingueneau (2004, p. 381) encontramos, no verbete relativo à polidez:

Enquanto, antigamente, a reflexão sobre a polidez se circunscrevia a tratados de caráter normativo - os "manuais "e outras obras da "literatura de etiqueta" (...) - ela deu lugar, recentemente, a

5 No original: "Don't impose; Give options; Make the listener feel good; Be friendly".

Fávero LL, Andrade MLCVO. Cortesia verbal e ensino de língua: reflexôes sobre competência comunicativa, jogo interpessoal e normatividade 
uma multiplicidade de estudos tanto teóricos quanto descritivos: trata-se de verificar que lugar a polidez ocupa e que papel ela desempenha nas interaçóes cotidianas, e de descrever o conjunto dos procedimentos postos em funcionamento para preservar o caráter harmonioso da relação interpessoal; procedimentos extremamente numerosos e diversos que, longe de estarem confinados às famosas "fórmulas", mobilizam na verdade uma parte importante do material produzido na iteração.

\section{A PROPOSTA DE BROWN E LEVINSON}

A noção de imagem social foi retomada por Brown e Levinson na obra Politeness -Some universals in language use (1987), como ponto de partida para sua proposta. A imagem (face - want = desejo de preservar a imagem) é universal em si mesma e o que varia entre as culturas são traços particulares que constituem a imagem pública desejada.

As denominaçóes de face e território são rebatizadas como face positiva e face negativa, respectivamente. A face negativa é o desejo de liberdade de ação e o domínio do conjunto dos territórios do eu, e a positiva, o desejo de ser aceito pelos outros e de que estes compartilhem os mesmos desejos.

As diversas situações interacionais criam conflitos que podem pôr em perigo a imagem pública dos interlocutores, quer dizer, todos os atos que produzimos, denominados por eles face threatering acts (FTAs), são de alguma forma ameaçadores, isto é, são açóes que ameaçam a imagem pública.

O locutor procura suavizar esta ameaça com a cortesia (em nenhum momento definida por eles) que surge como "um meio de conciliar essa ameaça com o desejo místico de preservação das faces" e, para isto, tende a selecionar alguma estratégia de conduta.

O emprego de uma ou outra estratégia depende de três fatores:
a) relação de poder entre os interlocutores;
b) distância social entre eles;
c) normas de conduta impostas por determinada cultura.

Fávero LL, Andrade MLCVO. Cortesia verbal e ensino de língua: reflexôes sobre competência comunicativa, jogo interpessoal e normatividade 
Brown e Levinson apresentam quinze estratégias de cortesia positiva, dez de negativa e quinze de indiretividade (off record), ${ }^{6}$ que não se dão de forma estanque, mas se combinam em muitos casos, sendo difícil, às vezes, precisar quais foram utilizadas. Note-se, também, que elas podem se manifestar por inúmeras marcas linguísticas e somente algumas são apresentadas neste trabalho

A proposta, uma das mais influentes, recebeu inúmeras críticas, como a de Kerbrat-Orecchioni, descrita a seguir e citada por Alija. "É como se não fosse possível dar um passo sem ameaçar a imagem pública, própria e alheia”(Alija, 2005, p. 333).

\section{REVISÁO DA PROPOSTA DE BROWN E LEVINSON ELABORADA POR KERBRAT-ORECCHIONI}

Kerbrat-Orecchioni (2005, p. 196). afirma ser a proposta de Brown e Levinson "redutora" e excessivamente pessimista, pois considera os indivíduos como que "vivendo sob a ameaça constante dos FTAs, em todos os gêneros e usando seu tempo na vigilância de seu território e sua face" 7 .

Diz, ainda, que esta é uma concepção defensiva porque aparece como um mal menor e que, se muitos atos são potencialmente ameaçadores dessas mesmas faces, outros, ao contrário, são, antes, valorizadores dessas mesmas imagens, como os cumprimentos, os agradecimentos, os votos de confraternização, etc.

Apresenta, então, ao lado dos FTAs de Brown e Levinson, os Face Flattering Acts (FFAs) ${ }^{8}$, atos lisonjeadores, valorizadores das faces. A proposta repousa sobre três noções fundamentais:

- face negativa $\mathrm{x}$ face positiva;

- $\quad$ FTAs x FFAs;

- cortesia negativa $\mathrm{x}$ cortesia positiva .

6 Dadas as limitaçôes de um trabalho desta natureza, elas não serão aqui relacionadas.

7 No original: "vivant sous la ménace permanente des FTAs en tous genres, et passant leur temps à montrer la garde autour de leur territoire et de leur face”.

8 Já em trabalho de 1992, a autora apresentara os anti-FTAs que tinham, porém, o inconveniente, segundo ela, de manter uma dissimetria no sistema, deixando entender que eles seriam marcados em relação aos FTAs.

Fávero LL, Andrade MLCVO. Cortesia verbal e ensino de língua: reflexôes sobre competência comunicativa, jogo interpessoal e normatividade 
$\mathrm{O}$ ato pode ser um FTA, um FFA ou um ato misto, uma mistura dos dois, nos seguintes casos:

1. O ato é intrinsecamente misto, como o oferecimento e o cumprimento, considerados por Brown e Levinson como FTA, pois são, antes de tudo, uma manifestação da inveja: o objeto elogiado é sempre cobiçado e, assim, ameaçador para a face negativa do cumprimentado, mas é também um FFA para sua face positiva. Segundo o contexto, um deles pode ter mais peso - geralmente o FFA, mas, dependendo da situação, as coisas podem se inverter. A autora lembra o caso de certas sociedades em que o ato está associado ao mau olhado e deve ser acompanhado de alguma fórmula de esconjuro.

2. A mesclagem dos FTAs e FFAs surge em virtude de inferências. O agradecimento, exemplo de FFA, pode comportar subentendidos que o restringem.

Exemplo: Ao chegar a uma festa e ver que os amigos não o cumprimentam pela formatura dias antes, o locutor A diz-lhes: -Obrigado, pelos efusivos cumprimentos.

\section{JOGO INTERPESSOAL E NORMATIVIDADE}

Cabe ressaltar, pelo exposto até este ponto, que a cortesia verbal pode ser evidenciada de múltiplas formas (no português, podemos expressar a cortesia empregando expressôes como "por favor", "me desculpe", "você poderia", algumas formas de tratamento, graduação de atos de fala ilocucionários, etc) dado que há diversas estratégias de mitigação e reforço e que elas dependem não só do contexto sociocultural, mas também do contexto situacional em que a interação ocorre, fazendo com que os interlocutores selecionem determinadas expressões que apontam uma dimensão socio-estilística (cf. Müller, 2006, p. 158).

Nessa perspectiva, a cortesia verbal deve ser analisada tomando a polaridade como um continuum que nos permite posicionar as análises tanto em uma direção mais sistêmico-pragmática, por um lado, como uma direção mais sociolinguístico-interacional, por outro, conforme destaca Müller (2006, p. 158): "a seleção de uma posição próxima a um pólo não exclui automaticamente a possibilidade de considerar o outro". Quando um locutor faz um pedido a seu interlocutor, pode fazê-lo de várias maneiras: o grau de cortesia pode variar segundo o contexto comunicativo no qual a mensagem é produzida, dependendo por exemplo da relação de maior intimidade ou não existente entre os interlocutores (identidade social, Grice, 1968; contrato conversacional, Fraser \& Nolen,

Fávero LL, Andrade MLCVO. Cortesia verbal e ensino de língua: reflexôes sobre competência comunicativa, jogo interpessoal e normatividade 
1981), daí a escolha da forma linguística empregada: se são amigos íntimos e dependendo da região do Brasil, podem usar o pronome tu (Me passa o relatório) ou a forma de tratamento você (Me diga a verdade); caso seja uma interação entre patrão e empregado, poderá ocorrer o uso da forma o senhor (Senhor X, envie-me o relatório o mais rápido possível, por favor!).

Entretanto, o caráter ilocucional da forma linguística selecionada sempre será a do pedido, ainda que tal forma linguística seja diversa e apresente um grau de cortesia variado (ordem, imposição, favor, solicitação a depender da entonação empregada), conforme o jogo interacional revele aspectos diferenciados da situação em foco e seja um parâmetro preliminar para o estudo da cortesia verbal.

\section{GÊNERO DISCURSIVO E INTERAÇÃO CORTÊS}

Na visão de Fairclough (1989), o gênero discursivo constitui mais que uma forma de organização da interação entre os homens, pois trata-se de uma atividade social que implica processos de produçáo, distribuição e consumo de texto, dado que a linguagem em uso apresenta funçóes relativas à ação, à representação e à identificação social. Assim, ao interagir com o outro o locutor negocia significados que atendem aos propósitos de uso da linguagem: entender e representar o contexto social e influir/agir sobre o(s) outro(s), empregando recursos linguísticos que projetam significados relacionados ao contexto de situaçáo (registro na terminologia de Halliday e Matthiessen, 2004) e com o contexto de cultura (ou gênero discursivo).

A interação deve ser vista, conforme Van Dijk (1992, p. 89), como "uma ação social”, ou seja, uma sucessão de açôes praticadas por vários indivíduos. A definição do autor tem como elemento básico o envolvimento interpessoal, pois concebe que os participantes são agentes implicados em um processo que deve seguir convençôes sociais e pragmáticas, em que os participantes realizam ou podem realizar alteraçóes da situação de maneira consciente e com um objetivo determinado. Para isso, alguns requisitos cognitivos e sociais precisam ser cumpridos durante a açáo interativa do agente, a fim de afetar ou alterar o outro (o interlocutor) mediante atos de fala, dado que a interação compreende uma sucessão de ações concatenadas e determinadas por limitaçôes espaço-temporais e sujeitas a regras sociais (direitos e deveres). Assim, o sentido das relaçóes estabelecidas entre os participantes depende de fatores cognitivos e pragmáticos, de forma que os enunciados sejam adequados e possam ser compreendidos em um contexto social, que influi nas açóes do sujeito enunciador e em sua relação com os demais participantes da atividade interacional.

Fávero LL, Andrade MLCVO. Cortesia verbal e ensino de língua: reflexões sobre competência comunicativa, jogo interpessoal e normatividade 
Nessa perspectiva, enunciador e enunciatário (entrevistador - entrevistado, missivista - leitor) praticam açóes, em determinado momento e espaço, visando a uma interaçáo que produza significados partilhados, estabelecendo vínculos por meio de troca de informaçóes, opiniōes, pontos de vista, sentimentos, emoçóes, etc. Nesse sentido, a interação social é um processo em que os participantes precisam saber "gerenciar" as relações interpessoais, dado que se trata de uma ação em conjunto, em que é necessário usar a linguagem, observando o contexto de situaçáo (registro) e o contexto de cultura (gênero discursivo), os papeis dos parceiros na situação, buscando construir um discurso em que haja colaboração e envolvimento.

Nos textos aqui examinados, enunciador e enunciatário têm nível sociocultural alto e se utilizam de um registro formal/semiformal, embora saibamos, fato já registrado por autores como Briz (1995) que não há uma linha divisória entre registros (por exemplo entre registro formal e informal), mas um contínuo de traços que permitem identificar registros intermediários, dependendo do tipo de carta e de entrevista e, no caso desta última, das características do programa de TV ou de rádio em que está inserida ou do grau de conhecimento partilhado e amizade, entre os interlocutores, quando pode assumir por exemplo um caráter distenso, como na entrevista da qual reproduzimos um trecho abaixo.

A seguir observamos um segmento de entrevista realizada, no dia 11 de agosto de 2013, por Marília Gabriela com o ex-jogador de basquete Oscar Schimidt, no programa "De frente com Gabi"”:

L1 ei Sílvio...tô de frente hoje com o MÃO SANTA...o maior dos maiores ídolos do esporte brasileiro... (...)

L1 O::Oscar muito obrigado por ter aceito o convite::

L2 ahn o prazer é meu

L1 como é que você está se sentindo?

L2 bem

9 O texto foi transcrito seguindo as normas estabelecidas pelo Projeto NURC. Em síntese, temos: ... qualquer pausa; O:: alongamento de qualquer vogal; [ simultaneidade de vozes; BraSIL entoação enfática.

Fávero LL, Andrade MLCVO. Cortesia verbal e ensino de língua: reflexôes sobre competência comunicativa, jogo interpessoal e normatividade 
L1 como está indo o tratamento?

\section{(...)}

L2 eu sou Gabi o maior palestrante do BraSIL...dois metros e cinco

L1 (risos) bobo...como é que é...uma...uma

$(\ldots)$

L2 voltei para cá... para me liberar de lá...meni::na... vou te falar (...); BraSIL entoação enfática

Temos aqui um exemplo de registro coloquial, pois a entrevistadora já inicia com um ei Sílvio, dirigindo-se provavelmente a Sílvio Santos, o dono do SBT e continua com o tratamento informal você; em determinado momento chama-o carinhosamente bobo e o entrevistado comporta-se também de maneira informal: você, menina.

Há, porém, uma nítida diferença entre a entrevista de TV ou de rádio e a conversação informal: na entrevista, a cada pergunta deve haver sempre uma resposta e a tomada de turno é pré-determinada (Alberda Marco, 2004). Além disso, a entrevista é dirigida a dois tipos de destinatário: o entrevistado e o público silencioso que está na frente do aparelho de TV ou do rádio, que não interfere diretamente, mas que tem um papel importante, pois a interação se desenvolve em função dele e é preciso mantê-lo como aliado, como bem sabem os que aí trabalham, isto é, não se pode perdê-lo em momento algum, pois a ele é permitido mudar de canal ou de estação.

Outro exemplo encontramos na entrevista realizada pelo jornalista Otto Lara Rezende no programa Painel da Rede Globo, em 1977, com Vinicius de Moraes:

Apresentador - ...Vinicius de Moraes está aqui no Painel para uma conversa com um amigo: Otto Lara Rezende

Entrevistador - Marcos Vinicius da Cruz de Melo Moraes...quem é você Vinicius? não...o Vinicius público...o Vinicius do show...o Vinicius da música popular...o Vinicius vedete...o Vinicius que todo mundo conhece...mas quem é o Vinicius...que nấo se conhece?

Fávero LL, Andrade MLCVO. Cortesia verbal e ensino de língua: reflexôes sobre competência comunicativa, jogo interpessoal e normatividade 
Entrevistado - eu...

Entrevistador - que não se conhece que NÃO ... que a GENte não conhece Entrevistado - eu ainda não sei muito bem não...sabe Otto eu acho que ...que sou um labirinto em busca de uma...de uma porta sa/saída

É importante observar que o registro empregado corresponde a um registro semi formal, pois, como se sabe, são amigos pessoais, mantêm um grau de cumplicidade e proximidade grande mas preservam sua imagem pública, já assinalada pelo apresentador- Vinicius de Moraes está aqui para uma conversa com um amigo Otto Lara Rezende.. Tratam-se por você, Vinicius, Otto, mas na entrevista o tema, as perguntas, os papeis já estão a priori estabelecidos: quem é você Vinicius?

Ao selecionar um gênero discursivo para interagir com seu interlocutor (oficio, requerimento, carta, bilhete, telegrama, email, SMS, telefonema, conversação face a face, entrevista, debate, etc), o enunciador também escolhe uma variante linguística para construir seu discurso, o que significa dizer que os textos revelam como a língua reflete elementos do contexto social em que o discurso se instaura. Sendo assim, o grau de cortesia verbal será expresso de modo variado e por meio de recursos linguísticos selecionados, dependendo da relação interpessoal existente entre os interlocutores, isto é, os papeis sociais que cada um representa dentro do grupo, a modalidade da interação localmente estabelecida, o esquema geral da atividade conversacional, entre outros, poderá haver alteração no contrato conversacional estabelecido, permitindo uma reorganização interativa do contexto.

Essa alteração pode ser observada em entrevistas ou debates televisivos ou ainda em uma animada conversação entre amigos durante uma festa, por exemplo. Em contextos como os citados, não se considera descortês que as interrupções aumentem no decorrer da interação. Trata-se, pois, de uma alteração das condições básicas da interaçẫo que, progressivamente, vai construindo um novo quadro cooperativo, na medida em que determinados elementos vão se modificando no contexto situacional. Para Müller (2006, p. 160) a noção de contrato conversacional é um modelo conceptual significativo para se analisar a cortesia verbal, pois permite compreender como os recursos linguísticos são empregados na constituição de um novo acordo social.

Quando analisamos a carta pessoal, verificamos que a interação entre missivista e leitor pode ser observada por uma dialogicidade inscrita no texto através de marcas específicas, selecionadas pelo enunciador, que revelam uma relação de maior proximidade ou distância em relação ao leitor.

Como é sabido, a escrita epistolar busca atender às necessidades próprias de cada grupo social, popularizando-se entre as pessoas que encontram nessa

Fávero LL, Andrade MLCVO. Cortesia verbal e ensino de língua: reflexôes sobre competência comunicativa, jogo interpessoal e normatividade 
prática discursiva uma maneira de estabelecer contato com conhecidos, amigos ou parentes. Tal contato estabelecido na correspondência particular revela uma interação mais distante ou mais próxima, devido a relaçóes de poder ou cumplicidade instauradas entre os interlocutores.

As condiçóes de Distância e Proximidade (cf. Koch e Oesterreicher (2013) comportam elementos que podem ser localizados de acordo com o tipo de carta particular em foco (entre conhecidos, amigos ou parentes). Desse modo, podemos encontrar cartas em que se destacam maior ou menor grau de poder, cumplicidade, afetividade, expressividade, entre outros.

A configuração do gênero carta comporta determinados elementos fixos e um alternativo. Entre os elementos fixos, temos os contextualizadores, que correspondem às indicaçóes de local de procedência da carta, data e assinatura de autoria. Trata-se, pois, de elementos que ancoram o texto. Quanto ao elemento alternativo, corresponde ao P.S.: Post Scriptum. Em carta a Mindlin, Ana Miranda acrescenta o seguinte P.S. "Como eu faço para acabar com as traças nos meus livros?.

Além desses componentes, localizamos o endereçamento e aqui já podemos evidenciar as relaçóes de poder e um grau maior de cortesia (Ilmo. Sr. Domingos Borges de Barros, Exmo. Sr.; ou Prezado Senhor José Mindlin) ou cumplicidade (Querido Amig; Mário Amigo; Caro Mário; Meu Caro Midlin; Caríssimo José Mindlin; Lygia, sempre querida; Minha querida filha, etc.) ou simplesmente o nome do interlocutor sem qualquer marca de cortesia, mas revelando proximidade (Sérgio, Chiquinho). Tem-se ainda abertura (introdução do tema a ser tratado), o desenvolvimento (aqui se localizam as sequências (narrativa, descritiva, explicativa, argumentativa, injuntiva, dialogal) e o fechamento. No final, há as despedidas que também podem ser mais formais e corteses(Atenciosamente: A sua disposição: Muito grato) ou mais informais (Um grande abraço; Afetuoso abraço, Muito amor) e a assinatura do missivista.

Veja-se, a seguir, a reprodução de três cartas pessoais: 


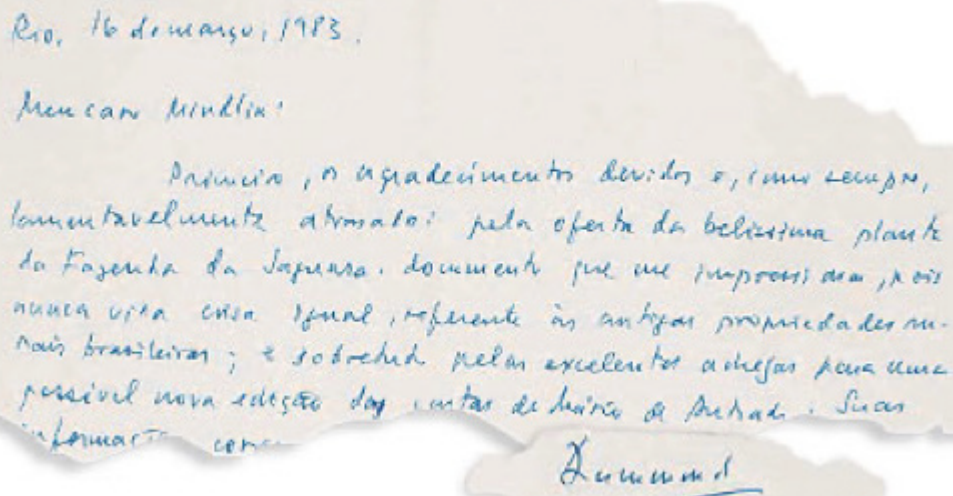

Figura 1. Carta de Carlos Dummond de Andrade a José Mindlin, escrita em 1983.

Fonte: Cartas da biblioteca Guita e Mindlin (2008, p. 182-183)

Neste trecho em que indicamos apenas o início da carta, verificamos que o enunciador introduz o tema da carta agradecendo a documento recebido anteriormente e contendo informaçóes importantes. No final, o enunciador despedese dizendo: "Nossas lembranças a Guita. O abraço afetuoso e grato do Drummond". Tem-se, portanto, uma carta em que a cortesia é marcada por relaçóes de cordialidade, afeto e amizade.

Fávero LL, Andrade MLCVO. Cortesia verbal e ensino de língua: reflexóes sobre competência comunicativa, jogo interpessoal e normatividade 


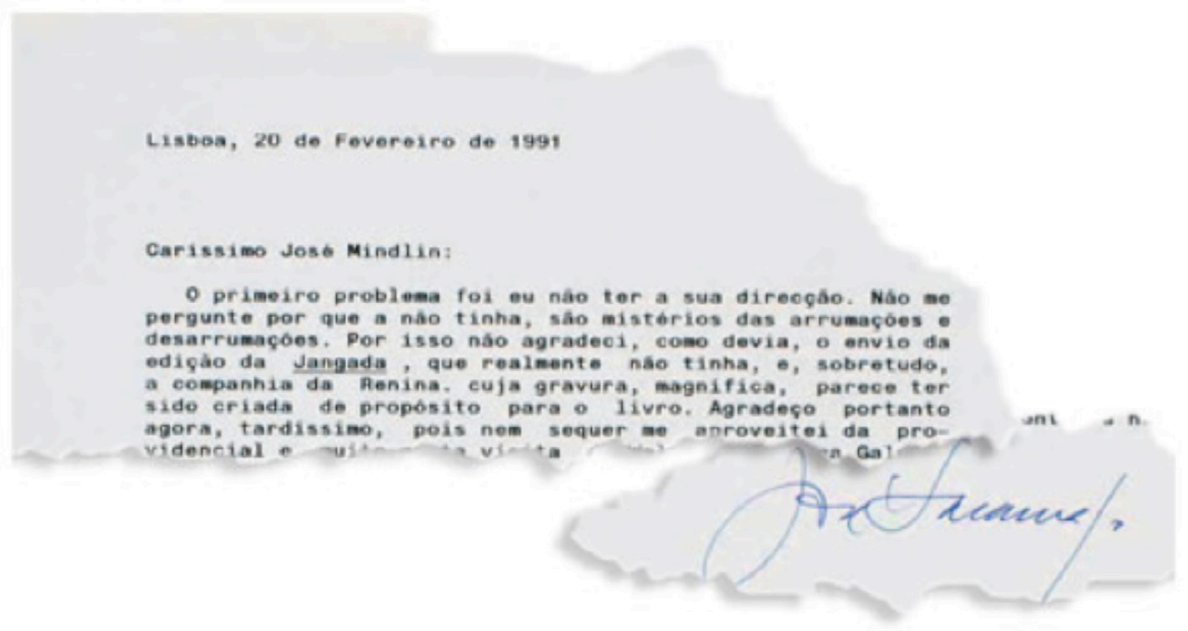

Figura 2. Carta de José Saramago a José Mindlin, escrita em 1991.

Fonte: Cartas da biblioteca Guita e Mindlin (2008, p. 193).

Neste segmento, o missivista pede desculpas ao interlocutor por não ter agradecido o envio da edição do livro "Jangada" e explica seus motivos. Nota-se a preocupação do enunciador em manter relaçóes de cortesia e amizade e explicar a sua falha. No encerramento da carta, o enunciador envia "abraços e saudades" e a assinatura.

Fávero LL, Andrade MLCVO. Cortesia verbal e ensino de língua: reflexões sobre competência comunicativa, jogo interpessoal e normatividade 
Rio, 22 de junho, 1980

Lygia, sempre querida:

Você se livrou da sua gripe em Lindoia? Espero que sim. Me assustou um pouco você dizer que seus pulmões não são brilhantes. Excesso de cigarro, talvez? Olhe bem isso, nada de exigir demais do irmlo-corpo, e também nada de embalá-lo com a ilusào de fumar. que vai destruindo devagar o edificio da gente.

Fiquei confortado ao saber que vocé me precedeu na experiéncia do cobreiro, um laço a mais a nos unir. Mas pelo visto, o seu foi um cobreiro legitimo e terrivel; o meu, apesar de legitimo (os médicos o garantiram) é vagabundo e incessante. Năo dói mais que o necessário para me chatear, dia e noite, com pequenas pausas de analgésico e sonifero. E já se vão dois meses e não passa! Ando descrente dos médicos e agora só confio no $\mathrm{Dr}$. Tempo, na Dra. Pacięncia e na reza de vocé ao quase beato Anchieta; menos pelo beato do que por você, amiga-irmã do fundo do coraçăo. Vou me adaptando à convivéncia com essa nevralgia do trigèmio, resultante do herpes, e penso que Maria Julieta suporta coisas muito maiores e mais trágicas, com a possivel resisténcia, que tem momentos de queda, mas depois se apruma e se reteza. E a vida!

Estou muito curioso de ver a sua Disciplina do Amor, cujos trechos por mim conhecidos são notáveis de concisão e força. Ha de ser um livro duro, cortante, massacrante, que a gente ama com amor doloroso. Năo sei até que ponto seu filho terá razlo aconselhando a identificaçăo nominal com a personagem do diário. Näo há mal em que você assuma, como ele disse, mas também uma verdade eternamente válida em arte é que cu sou outro. E esse outro tem o nome dele, que não é necessariamente o meu. Por mim (mas năo quero influenciar nada, examino apenas teoricamente a questăo) eu poria o nome inventado, justamente para dar idéia de imvençào a uma obra literária. Podemos confessar tudo, até o que não confessamos a nós mesmos, pelo recurso da transposiçāo artística. Quem não sabe que Machado de Assis foi um assassino e um violador nato, apesar de nunca o haver sido senlo através de seres imaginários? $O$ que há de perversidade naquele velhol E tão respeitável cá fora, o bandido.. Ele assaltava casas, fazia de vampiro de almas, destruia, desmoralizava os melhores sentimentos... e foi um digno fundador da Academia de Letras!

Repito, os fragmentos săo admiráveis. Que venha depressa o livro. E que todos dois tenhamos saúde, se não for a ideal, pelo menos a razoável, vocé com os seus pulmð̋es livres de qualquer agressão, eu com o meu herpezinho atipico, sempre pertos um do outro, sempre fraternos, sempre amorosos de puro amor.

Beijos, saudades do

\section{Carlos}

Figura 3. Carta de Carlos Dummond de Andrade a Lygia Fagundes Telles, escrita em 1980.

Disponível em www.literal.com.br

Neste exemplo, temos uma carta completa e podemos verificar todos os componentes da correspondência pessoal. Já no vocativo (Lygia, sempre querida), pode-se observar o grau de envolvimento e amizade existente entre os interlocutores, que se reitera mais adiante, no segundo parágrafo, quando o enunciador diz: "menos pelo beato do que por você, amiga-irmã do fundo do coração". No

Fávero LL, Andrade MLCVO. Cortesia verbal e ensino de língua: reflexôes sobre competência comunicativa, jogo interpessoal e normatividade 
primeiro parágrafo, o missivista introduz a carta com uma pergunta "Você se livrou da sua gripe em Lindoia?" E de modo cortês complementa: "Espero que sim".

Depois de comentar sobre problemas de saúde, passa a tratar de literatura, afirmando sua curiosidade de ver o livro "Disciplina do Amor", tecendo elogios à parte que já pode ler. Faz ainda algumas sugestóes para o trabalho da amiga e termina com mais elogios "os fragmentos são admiráveis. Que venha depressa o livro". Termina a carta com a frase "Beijos, saudades do Carlos".

\subsection{As entrevistas}

Selecionamos, como objeto de análise, trechos de entrevistas concedidas pela professora Gilda de Mello e Souza, duas à Rádio Cultura de Assis, Estado de São Paulo, uma ao professor Antônio Dimas e outra à professora Walnice Nogueira Galvão, publicadas recentemente no livro organizado por esta última, A Palavra Afiada. Nelas devemos observar a importância do contexto situacional em que se inserem. Partindo de Briz e Grupo Val.Es.Co.(1995), Albelda Marco (2004) afirma que as situaçóes comunicativas se criam a partir de um conjunto de fatores situacionais que se reduzem geralmente a quatro:

- relação de maior/menor igualdade social entre os interlocutores; relação de desigualdade funcional;

- relação de vida: maior/menor desconhecimento mútuo;

- interação não cotidiana;

- temática mais ou menos especializada. No nosso caso, elas são especializadas, o que vai acarretar temas a priori estabelecidos, papeis, perguntas etc.

\section{Assim, vejamos}

1. Primeira entrevista de Gilda de Mello e Souza à Rádio Cultura de Assis, em 1959

RCA - Acredita que essa experiência amadorística, como a senhora mesma a rotulou, tenha tido alguma importância na carreira futura da atriz [Cacilda Becker

GMS - Sim, acredito (...) eu me explico.

\section{(...)}

Fávero LL, Andrade MLCVO. Cortesia verbal e ensino de língua: reflexôes sobre competência comunicativa, jogo interpessoal e normatividade 
GMS (...) De tal forma que, se podemos dizer que Cacilda foi a primeira grande atriz desse renascimento teatral, Ziembinski foi o primeiro grande diretor

RCA - E ambos mais tarde se encontrariam, trabalhariam juntos e fundariam uma companhia?

GMS - O senhor me tirou a palavra da boca

RCA - Mas, um momento: a senhora afirmou que a Cacilda foi a primeira grande atriz desse renascimento e Ziembinski o primeiro grande diretor. Quer dizer que antes deles não havia teatro no Brasil? Não estará esquecendo Dulcina, Procópio, Jaime Costa e outros? Acaso não estavam eles representando, nessa mesma ocasiáo, em nossos palcos?

GMS - A sua objeção vem muito a propósito

RCA - Então, se bem entendo, a senhora considera Cacilda Becker a grande atriz brasileira do momento?

GMS - Sim; o senhor sentiu bem o que quero dizer (...)

RCA - Poderia focalizar algumas características do teatro de Machado de Assis?

RCA - Poderia dar-nos uma idéia dessa peça?

GMS - Pois não. É uma comédia de um só ato, em que aparecem quatro personagens...(...)

2. Segunda entrevista concedida à Rádio Cultura de Assis - 1959

GMS - É a segunda vez que venho à presença dos ouvintes da Rádio Cultura de Assis para falar sobre teatro. Creio estou criando um pequeno hábito. Mas dentro

Fávero LL, Andrade MLCVO. Cortesia verbal e ensino de língua: reflexôes sobre competência comunicativa, jogo interpessoal e normatividade 
de dois dias iremos receber a visita de um dos conjuntos mais significativos de São Paulo - o Teatro de Arena - e é esse o motivo que me traz novamente ao microfone.

RCA - Perdão se logo de início a interrompo, mas...

GMS - À vontade, é bom que o nosso diálogo seja, desde o início entrecortado. Pode perguntar...

RCA - É um esclarecimento. Pelo que sei o Teatro de Arena é um pequeno conjunto que representa num recinto acanhado, dispondo de poucos lugares e de limitados recursos econômicos; a sua importância seria, pois, mais artística do que comercial...

GMS - Sem dúvida.(...)

RCA - Podia citar algumas das revelações do Teatro de Arena?

GMS - Podia citar várias a começar pelo seu diretor....

RCA - E já que falou em Gimba, permita-me a pergunta: qual da duas peças de Guarnieri prefere, Eles não usam Black- tie ou Gimba?

GMS - Prefiro, sem sombra de dúvida Eles não usam Black-tie

As entrevistas se realizam no estúdio da rádio, com temática especializada - na segunda, a entrevistada diz, logo no início - É a segunda vez que venho à presença dos ouvintes da Rádio Cultura de Assis para falar de teatro. A interação é não cotidiana, com pouca ou nenhuma relação de proximidade. $\mathrm{O}$ registro é formal, tanto entrevistador quanto entrevistada mantêm uma distância cerimoniosa e extremamente cortês, tratam-se sempre por senhor e senhora. $\mathrm{O}$ entrevistador diz:

- perdão se logo no início a interrompo... (segunda entrevista)

E a entrevistada: À vontade, é bom que o nosso diálogo seja, desde o início entrecortado.

E mais adiante o mesmo entrevistador: permita-me a pergunta.

Fávero LL, Andrade MLCVO. Cortesia verbal e ensino de língua: reflexões sobre competência comunicativa, jogo interpessoal e normatividade 
Outro ponto a ser observado é o uso dos tempos verbais: imperfeito do indicativo e futuro do pretérito, formas utilizadas aqui para exprimir a vontade do entrevistador, mas de modo cortês e comedido, sem impor.

3. Na entrevista concedida a Antônio Dimas para a revista Almanaque - Cadernos de Literatura e Ensino, n. 8, em 1978, alguns desses traços se repetem, como podemos ver a seguir:

AD - Podia nos dar uma ideia do que é O banquete, texto de Mário de Andrade que a Livraria Editora Duas Cidades acaba de lançar?

GMS - O banquete é o último livro dos grandes textos teóricos deixados por Mário de Andrade. Trata-se de uma reflexão em registro satírico e em forma de diálogo, onde o escritor procura sintetizar as linhas mestras e os temas principais de seu pensamento estético (...)

$\mathrm{AD}$ - Como situa O banquete no conjunto da obra de Mário de Andrade?

GMS - A meu ver este texto representa o que Mikhail Bakhtin chama "um diálogo do limiar”, isto é, um escrito provocado pela situação pré-mortuária que(...)

GMS - (...) Quanto a mim prefiro interpretar a forma dialogada de $O$ banquete como imposição da própria personalidade do escritor

AD - Poderia desenvolver essa afirmação

Nesta entrevista, concedida a um colega de Universidade, mantém-se o registro formal, observado nas duas primeiras, talvez devido ao fato de ser o entrevistador um jovem professor em início de carreira e GMS uma professora de renome (relação funcional e vivencial entre os interlocutores). Em nenhum momento, Antônio Dimas utiliza algum pronome de tratamento (você ou senhora), dizendo sempre: poderia - como situa - fato que não ocorre na última entrevista, a de número 4, por nós selecionada, concedida por GMS a Walnice Nogueira Galvão, em 1984, também colega de universidade, mas ligada a ela por laços de amizade. 
GMS - Se vocês estiverem de acordo, eu gostaria de começar esta nossa conversa retomando um tema que já abordei noutro momento mas não soube desenvolver. $\mathrm{O}$ ano passado, ao relembrar numa das reunióes da SBPC a marca deixada pelos professores franceses nas primeiras turmas da jovem Faculdade de Filosofia, mencionei de passagem a influência decisiva que também foi para nós aquela nova oportunidade de convívio. Convívio não só de professores e alunos, mas entre colegas.

\section{(...)}

WNG - Vocês saiam muito juntos? Onde se encontravam, como se divertiam?

GMS - Saíamos muito juntos. A partir de certo momento, creio que só conseguíamos nos divertir se estivéssemos juntos. Em geral, nos encontrávamos no fim da tarde, nas aulas do Maugué, que por essa altura eram ministradas no $3^{\circ}$. Andar do Instituto de educação da Escola Caetano de Campos, onde funcionavam algumas seçôes da faculdade (...)

WNC - Já que estamos fazendo o registro cronológico de sua iniciação artística, fale um pouco de literatura. Quais eram os livros que vocês liam?

GMS - Bem, este ponto é muito comprometedor, pois revela mais facilmente as vogas da época do que nossa capacidade de discriminação. Por isto prefiro falar sobretudo em meu nome.(...)

WNG - Eu gostaria de voltar um pouco atrás para esclarecer um detalhe quanto à influência francesa que vocês receberam. Como é que tendo sofrido tão profundamente essa influência vocês não se afrancesaram?

GMS - Creio que nós não nos afrancesamos porque a influência da faculdade nos atingiu no momento exato (...)

\section{(...)}

GMS - Mas não fiz mais versos. E agora estou vendo que não respondi a sua pergunta. Fiquei divagando e me perdi...

WNG - Não faz mal. Eu vou repetir a pergunta: Mário teve alguma influência em sua entrada para a faculdade?

Fávero LL, Andrade MLCVO. Cortesia verbal e ensino de língua: reflexôes sobre competência comunicativa, jogo interpessoal e normatividade 
GMS -Na entrada para a faculdade, propriamente não, mas ele interferiu na escolha do curso. (...)

\section{(...)}

GMS - (...) Foi bem difícil para minha geração, harmonizar a carreira com a realização afetiva.

WNG - Você não está exagerando? E seu caso?

GMS - Meu caso é uma exceção. E se o nosso grupo foi pródigo em encontros afetivos que deram certo, conta poucos casais que conseguiram realizar carreiras paralelas, como hoje é corrente entre os ex-alunos da faculdade.

Nesta entrevista, o registro é, podemos dizer semiformal, pois a entrevistadora trata a entrevistada sempre por você numa relação de proximidade o que não ocorre nas três entrevistas anteriores; como já dissemos, elas eram, além de colegas de faculdade, amigas, o que permite que WNG lhe faça uma solicitação no imperativo: fale ou, usando o futuro do pretérito: Eu gostaria..., mas adiante a questione: Você não está exagerando?, mantendo, porém, sempre uma extrema cordialidade, com preservaçáo das faces. É necessário esclarecer que todas essas entrevistas apresentam-se impressas, portanto, faltam-nos outros elementos importantes para a análise, como os prosódicos e os gestuais. De qualquer modo, foram selecionadas porque revelam condiçóes de editoração que se tornam significativas para o processo de retextualização de uma entrevista, isto é, como passar de um registro sonoro para o registro gráfico, evidenciando uma atividade interessante para o trabalho linguístico na escola.

\subsection{As cartas pessoais}

Nas cartas pessoais, podemos observar que um grau maior ou menor de cortesia deve ser observado em relação ao contexto situacional em que a carta se insere. Devemos, por exemplo, verificar se a relação entre o missivista e seu leitor é uma relação entre amigos, familiares ou apenas entre colegas. Dessa relação, podemos encontrar situaçóes de menor grau de cortesia, mas que revele um maior grau de intimidade e mesmo de liberdade entre os interlocutores. Vejamos alguns trechos de cartas. 
1. Carta de Sérgio Milliet a Yan de Almeida Prado

Paris, 9-11-23

Meu caro Yan,

Mais duas cartas tuas e no entanto não me dizes se recebeste "La Findu Monde "com dedicatória e duas gravuras de Vernet, coloridas (...)

(...)Vou te mandar o numero da Amérique Latine onde sahir meu artigo sobre Klaxon.

Vocês são uns bananas. Deixaram Klaxon morrer é um crime de lesa-modernismo. Que diabo de falta de coragem e de "dévoúment". Reúnam-se, tentem uma offensiva, façam freje. Mas mexam-se" Ora bolas! Nós aqui num esforço tremendo e vocês a dormir". Dá vontade de trahir Klaxon. Vou (rasura) escrever um manifesto anti-kaxista, dizendo que vocês são românticos e que merecem guilhotina. Vamos! Fogo na cangica!

Adieu! Lembranças

ABRAÇOS,

Sege

Peço-te entregar o cartão Lumiére ao Guy. Ignoro o endereço dele interessa-o a notícia.

(Cartas da biblioteca Guita e José Mindlin, p. 102)

Nesse trecho, verificamos que a intimidade permite ao missivista denominar o amigo (caro Yan) e o grupo que publicava a revista Klaxon de "bananas", o que revela descortesia, mas indica proximidade, intimidade e liberdade para fazer críticas e ainda "ordenar" o que devem fazer e uma ameaça: "Vou [rasura] escrever um manifesto anti-klaxista, dizendo que vocês são românticos e que merecem guilhotina. Vamos! Fogo na cangica!", outro ato de ordem, comando. Entretanto, essa atitude descortês sugere liberdade entre os interlocutores e a possibilidade de dizer o que pensa sem restriçóes, pois entre amigos íntimos isso é permitido.

Fávero LL, Andrade MLCVO. Cortesia verbal e ensino de língua: reflexões sobre competência comunicativa, jogo interpessoal e normatividade 
2. Carta de Sérgio Buarque de Holanda a Mario de Andrade

Mario amigo,

Recebi sua cartinha de ontem e achei besta. V. tem o direito de tudo da gente menos dar a entender o que v. deu a entender (...)

$10 / 02 / 1926$

(Mário de Andrade e Sérgio Buarque de Holanda-Correspondência., p. 83)

Nesse pequeno segmento da carta, podemos constatar que o missivista Sérgio classifica a carta recebida de "besta", o que poderia ser descortês e caracterizar algo ofensivo, mas o enunciador busca em seguida explicar o mal entendido que houve entre eles ("V. tem o direito de tudo da gente menos...")

3. Carta de Mário de Andrade a Sérgio Buarque de Holanda

Sérgio, caro mio,

quase que assustei-me com o bilhete de você. Porém estou seguro da nossa amizade e inda sobre ela me assegurava o resto do bilhete. Você escreveu: "Você tem o direito de supor tudo da gente menos dar a entender o que vc deu a entender". Por Deus que não dei a entender coisíssima nenhuma! Com amigos nunca dou a entender, falo franco e rijo, te juro. Estive matutando no meu bilhete escrito a 200 quilômetros por hora e creio que seja aquilo de eu falar "pra você me mandar à merda" que você imaginou que eu imaginei que você estava me abandonando. Palavra que foi brincadeira sem mais nada. Se feri rasgue o bilhete porque... ((grifos do autor da carta))(13/02/1926)

(Mário de Andrade e Sérgio Buarque de Holanda - Correspondência p. 88-89)

Nesta resposta à carta, apresentada no exemplo 3, o missivista Mário diz ter ficado assustado com o tom da carta, mas "está seguro da nossa amizade e inda sobre ela me assegurava o resto do bilhete”. Afirma ainda que com amigos "fala franco e rijo". Observa-se também que, mostrando-se arrependido com o mal entendido, o enunciador escreve "pra você me mandar à merda". Pede desculpas pelo ocorrido, quando afirma: "Palavra que foi brincadeira sem mais nada. Se feri rasgue o bilhete...”.

Por meio dessas duas cartas, podemos dizer que o grau de intimidade e cumplicidade entre os interlocutores é bastante forte e que isso permite inclusive usar uma linguagem de baixo caláo, desrespeitando as normas de cortesia verbal.

Fávero LL, Andrade MLCVO. Cortesia verbal e ensino de língua: reflexôes sobre competência comunicativa, jogo interpessoal e normatividade 


\section{CORTESIA VERBAL: REFLEXÓES PARA O ENSINO DE LÍNGUA PORTUGUESA}

O tratamento da oralidade e da escrita no ensino de Língua Portuguesa pode ser efetivado na escola se o professor trabalhar com gêneros discursivos distintos, como enfocamos neste artigo (entrevistas de televisão, entrevistas impressas, cartas pessoais), que permitam observar a língua em seus diversos registros: formal, informal. Para tanto, o professor precisará desenvolver atividades em suas aulas que permitam o contato do aluno com textos que propiciem usos mais formais ou mais coloquiais da língua em diferentes graus de cortesia ou (des)cortesia verbal.

O estudo da cortesia verbal apresenta-se como uma alternativa educacional importante na contemporaneidade, visto que - como se viu neste artigo- a cortesia é universal, mas contém as especificidades culturais de cada grupo social, tornando necessário o seu conhecimento em uma sociedade globalizada, permitindo - assim - que situaçóes de constrangimento e conflito sejam evitadas. Diante dessas observaçôes, é importante que a escola promova um espaço teórico e metodológico para a elaboração e reflexão sobre formas condizentes de promover o convívio, a ética, mediado pelo uso da língua. Para tanto, é preciso desenvolver nos alunos a competência interativa, textual, trabalhando a cortesia, conforme destacam Silva Neto e Gheisens (2011, p. 109-110) e objetivando os seguintes pontos:
a) discutir a utilização de formas linguísticas para a expressão de atitudes corteses;
b) conhecer as regras que integram uma interação verbal cortês, em níveis verbais e não-verbais;
c) reconhecer e utilizar formas linguísticas que expressam comportamentos corteses em contextos interacionais variados;
d) utilizar formas linguísticas de cortesia em gêneros orais e escritos;
e) observar as variáveis sociais que determinam o nível de cortesia nas interações (dis- tância social, poder, cumplicidade, intimidade, envolvimento, distanciamento);
f) observar a cortesia como fenômeno de harmonização das interaçôes verbais e ma- nutenção da imagem dos interlocutores;
g) observar a cortesia coo estratégia retórica (visando à persuasão e sedução);
h) reconhecer e utilizar formas linguísticas que atenuam açôes verbais de natureza injuntiva (ordem, pedidos, instruçôes, entre outras).

A análise e reflexão das práticas de linguagem que evidenciam a cortesia verbal precisam ser conduzidas por meio de um ensino da língua que destaque os gêneros discursivos, uma abordagem sócio-interacional e as relaçôes contextuais.

Fávero LL, Andrade MLCVO. Cortesia verbal e ensino de língua: reflexôes sobre competência comunicativa, jogo interpessoal e normatividade 


\section{CONSIDERAÇÓES FINAIS}

O trabalho examinou, a partir de uma perspectiva pragmática, entrevistas de televisão, entrevista de rádio e entrevistas orais, posteriormente impressas e cartas pessoais, todas do século XX, publicadas em coletâneas de estudos literários.

Partindo de um breve percurso histórico, mostramos como a cortesia é um princípio regulador da conduta que cada comunidade estabelece para regular o comportamento adequado de seus membros, ajustando-o, às normas sociais, por meio de estratégias, dirigidas a amenizar as tensôes na interação.

Embora ela seja universal, suas formas variam de um grupo para outro, de uma cultura para outra, de um gênero para outro e, especialmente, de um contexto comunicativo para outro, dependendo, por exemplo da relaçáo de maior ou menor intimidade existente entre os interlocutores. (Grice, 2968; Fraser/Nolen, 1981).

Propusemos também uma reflexão como no mundo contemporâneo os estudos de Cortesia podem ser eficazes para o ensino de Língua Portuguesa na escola brasileira, promovendo o convívio interpessoal e a ética, mediados pelo uso da língua em interaçóes sociais diversas.

\section{REFERÊNCIAS}

Albelda Marco M. Cortesia en diferentes situaciones comunicativas. La conversación coloquial y la entrevista sociológica semiformal. In: Bravo D, Briz A (orgs.). Pragmática sociocultural: estúdios sobre el discurso de cortesia en español. Barcelona: Ariel; 2004. p. 109-134.

Alija FJG. La cortesia verbal como reguladora de las interaciones verbales. Actas del XVI Congreso Internacional de ASEL - La Competencia Pragmática o la Enseñanza del Español como Lengua Extranjera. Oviedo: Universidad de Oviuedo; 2005.

Alvarez-Muro A. Cortesía y descortesia: teoria y práxis de un sistema de significación. Mérida (Venezuela): Universidad de Los Andes; 2005.

Andrade MLCVO. (Des)cortesia e contestação em interações escritas. In: Preti D (org.). Cortesia verbal. v.9, Projetos Paralelos - NURC-SP. São Paulo: Humanitas; 2008. p. 193-214. 
Bernal M. Hacia una caracterización sociopragmática de la cortesia, la descortesía y la anticortesía. In: Bravo D (ed.). Estudios de la (des)cortesía en español: categorias conceptuales y aplicaciones a corpora orales y escritos. Buenos Aires: Editorial Dunken; 2005.

Bolivar A. Descortesia y confrontación política: un análisis crítico. In: Bravo D (ed.). Estudios de la (des)cortesia em español: categorias conceptuales y aplicaciones a corpora orales y escitos. Buenos Aires: Editorial Dunken; 2005. p. 273-297.

Bravo D. Actividades de cortesia, imagen social y contextos socioculturales: uma introducción. Actas del primer coloquio del programa Edice. Estocolmo: Universidad de Estocolmo; 2003.

Briz G A, GRUPO VAL.ES.CO. La conversación coloquial (Materiales para su estudio) Anexo XVI de Cuadernos de Filología. Valencia: Universitad de Valencia; 1995.

Brown P, Levinson S. Politeness some universals in language use. Cambridge: Cambridge University Press; 1987.

Charaudeau P, Maingueneau D. Dicionário de Análise do Discurso. São Paulo: Contexto; 2004.

Fairclough N. Language and power. London/New York: Longman; 1989.

Fairclough N. Discurso e mudança social. Brasília: Editora da Universidade de Brasília; 2001.

Fávero LL. Cortesia nas interações cotidianas. In: Preti D (org.). Cortesia verbal v.9, Projetos Paralelos - NURC-SP. São Paulo: Humanitas; 2008. p. 305-322.

Fávero LL, Andrade MLCVO, Aquino ZGO. Discurso e interação: a polidez nas entrevistas. In: Gärtner E, Hundt C, Schünberger A (orgs.) Estudos de linguística textual do português. Frankfurt amMain: TFM; 2000a. p. 217-230.

Fávero LL, Andrade MLCVO, Aquino ZGO. Papéis discursivos e estratégias de polidez nas entrevistas de televisão. Veredas: revista de estudos linguísticos. 2000b; 4: 67-77. Fraser B, Nolen W. The association of deference with linguistic form. International Journal of the Sociology of Language. 1981;27:93-109.

Goffman E. Interaction Ritual. New York: Pantheon; 1967. 
Goffman E. La mise em scène de la vie quotidienne. Paris: Minuit; 1973.

Goffman E. Forms of Talk. Phiiladelphia: University of Pensylvania Press; 1981.

Grice HP. Logic and Conversation. In: Cole P, Morgan J (eds.) Syntax and Semantics. Vol. 3: Speechs Acts. New York: Academic Press; 1968. p. 41-58. [Tradução para a língua portuguesa de João Wanderley Geraldi. Lógica e Conversação. In Dascal M (org.). Fundamentos Metodológicos da Linguística - vol. IV. Campinas: Editora do Autor; 1982. p. 81-104.

Halliday M, Matthiessen C. An Introduction to Functional Grammar. 3.ed. London: Arnold; 2004.

Kerbrat-Orecchioni C. Les interactioms verbales. T.II, Paris: Armand Colin; 1992.

Kerbrat-Orecchioni C. Le discourse en interaction. Paris: Armand Colin; 2005.

Koch P, Oesterreicher W. Linguagem da Imediatez - Linguagem da Distância: oralidade e escrituralidade entre a teoria da linguagem e a história da língua. Traduçáo de Hudinilson Urbano e Raoni Caldas. Língua d’Água. 2013; 26(1):154-174.

Lakoff R. The language of politeness. Papers from the Ninth Regional Meeting of the Chicago Linguistic Society.1973, p. 293-305

Leech G. Principles of pragmatics. London: Longman; 1983.

Mello e Souza G. A palavra afiada. Organização, introdução e notas de Walnice Nogueira Galvão. Rio de Janeiro: Ouro sobre azul; 2014.

Mindlin J (org.). Cartas da biblioteca de Guita e José Midlin. São Paulo: Editora Terceiro Nome; 2008.

Monteiro PM (org.) Mário de Andrade e Sérgio Buarque de Holanda: Correspondência. São Paulo: Companhia das Letras/IEB/EDUSP; 2012.

Moraes V. Entrevista no Programa Painel [site]. Disponível em: <http://youtu.be/1TsKPFkuUUk> Acesso em 20.03.2014 
Müller AP. La cortesía conversacional: análisis secuenciales. In: Schrader-Kniffki M(ed.) La cortesia en el mundo hispânico. Nuevos contextos, nuevos enfoques metodológicos. Frankfurt/Madrid: Vervuert-Iberoamericana; 2006. p. 157-182.

Schimdt O. Entrevista no programa De frente com Gabi [site]. Disponível em: < https:// www.youtube.com/watch?v=buUHwT6xaE4> Acesso em 18.03.2014

Silva Neto JG, Gheysens EPA. A cortesia verbal no ensino de língua portuguesa: reflexôes sobre a sequência didática. Litera Online. 2011;4:101-125.

Van Dijk TA. La ciencia del texto: un enfoque interdisciplinario. 3.ed. Barcelona: Paidós; 1992.

Fávero LL, Andrade MLCVO. Cortesia verbal e ensino de língua: reflexôes sobre competência comunicativa, jogo interpessoal e normatividade 